\title{
INTERFERENCE FIT SIMULATION ON PIN JOINT BY USING ANSYS
}

\author{
Mohammed Imran', Mohamed Haneef ${ }^{2}$, Syed Zameer ${ }^{3}$ \\ ${ }^{I}$ Assistant Professor, Department of Mechanical Engineering, Ghousia College of Engineering, Ramanagaram, \\ Karnataka, India \\ ${ }^{2}$ Principal \& Professor, Department of Mechanical Engineering, Ghousia College of Engineering, Ramanagaram, \\ Academic Senate member-VTU, Karnataka, India \\ ${ }^{3}$ Assistant Professor, Department of Mechanical Engineering, Ghousia College of Engineering, Ramanagaram, \\ Karnataka, India
}

\begin{abstract}
The present study objective is to investigate the effect of interference fit range of contact stress distribution of centrally holed plate, this will be used in riveted joints, permanent fasteners joints applications. There are a lot of studies are carried out related to the effect of interference fit to enhance the life of components, however, present work aims to study the effect of contact stress distribution of a interference fit by considering properties of Stainless Steel and Aluminium alloy.
\end{abstract}

Keywords: Interference Fit, Stainless Steel and Aluminium Alloy Materials, Contact Stresses and ANSYS.

\section{INTRODUCTION}

The fitting of components shows integrity joints to get interconnectivity between more than one assemblies like machine, structures etc. The most critical type of fit is interference fit when compared with a different fits.

Analysis of contact stress in rail and wheel discussed by Vahid Monfared et al [1], they are considered contact areas are elliptical, rectangular or circular and shows that results are useful for analyzing the creation of crack in critical surfaces and points then, finally define the agreement are found between finite element method (FEM) and previous analytical results for determination of contact stress in rolling bodies. And also the several investigation are done on contact pressure distribution and stress as [2]-[3]-[4]-[5] etc.

\section{PROBLEM DEFINITION AND SCOPE OF PRESENT WORK}

\subsection{Problem Definition}

In the current study analysis of a steel pin contacting a smooth pinhole in a plate is carried out to investigate the effect of Contact stress distribution. Because of the geometric symmetry of the model, the quarter symmetric model was taken to simulate the contact problem. The finite element model was built that is, plate with hole and pin member were modeled and meshed with Solid185 element and also postprocessor data are taken by using ANSYS software.

\subsection{Methodology}

> Dimensional plot, material properties are selected from literature survey.

$>$ Modeling, meshing, applying boundary conditions and analyzing the results using ANSYS

$>$ Initially carbon steel is used for the analysis contact stresses developed in pin joint.

$>$ Later aluminum material used to analyze the contact stress.

> Finally comparing results of both materials by considering under same design.

\subsection{Specification}

Structure

: 8 node solid 185

Meshing

Number of element division : 4

Boundary condition $\quad$ :Initial displacement $1.4 \mathrm{~m}$

Time taken

Material properties

$: 1 \mathrm{~min}$

: Using two materials as carbon steel and Aluminium

Both solids are made of structural steel and Aluminium alloy material properties (stiffness $=2.1 \times 10^{5} \mathrm{MPa}$, Poisson's ratio $=0.3$ and stiffness $=0.7 \times 10^{5} \mathrm{MPa}$, Poisson's ratio $=0.29$ ) and are assumed to be flexible.

The dimensions of the model

$$
\begin{aligned}
& \text { PIN } \\
& \circ \text { radius }=2 \mathrm{~mm}, \\
& \circ \text { length }=20 \mathrm{~mm}, \\
& \text { PLATE } \\
& \circ \text { width }=10 \mathrm{~mm}, \\
& \circ \text { length }=10 \mathrm{~mm}, \\
& \circ \text { depth }=4 \mathrm{~mm} . \\
& \text { PINHOLE } \\
& \circ \text { radius }=1.9 \mathrm{~mm}, \\
& \circ \text { depth }=4 \mathrm{~mm} .
\end{aligned}
$$




\subsection{Mesh Model}

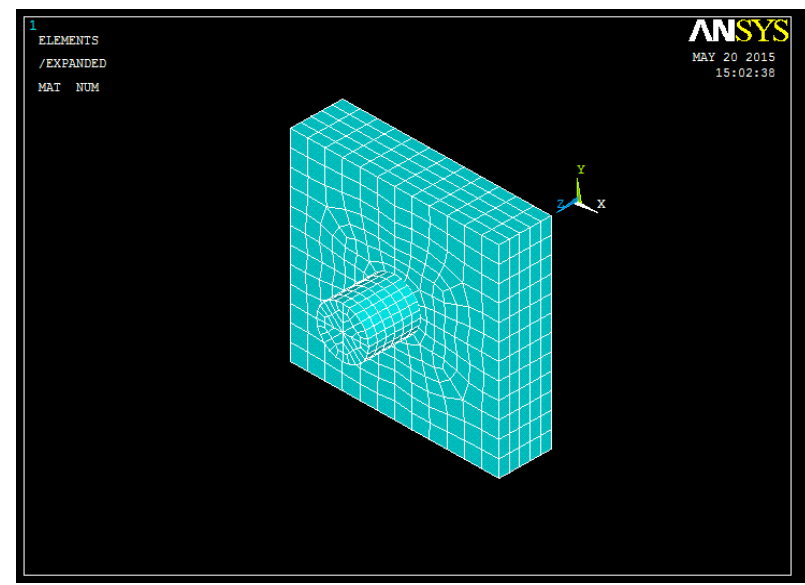

Fig-1: 3-Dimensional mesh element (Interference fit).

Fig -1 shows mesh model of 8noded solid element for both pin and plate in ANSYS. Mesh model is shows the quadrilateral 4-noded map meshed element with numbers of 4 element division in $\mathrm{Z}$ direction.

\subsection{Applied Boundary Condition}

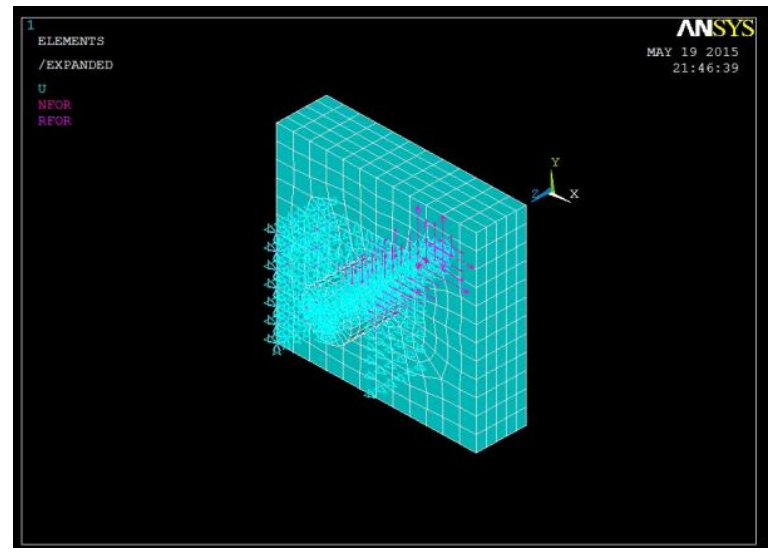

(a)

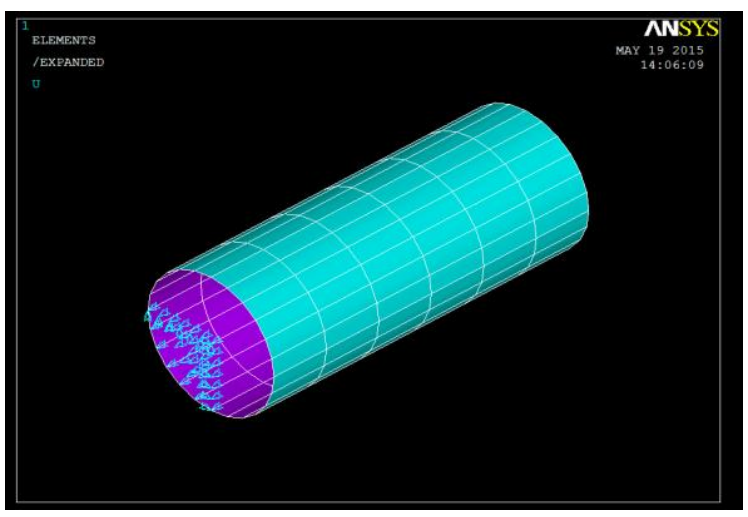

(b)

Fig-2. (a) Two Step Boundary Conditions (b) Contact pair Boundary Conditions.

Fig-2 (a) shows two step boundary condition is applied on pin and plate. Load step 1 of interference fit will be set to solve the problem with no additional displacement constraints to observe the interference stresses caused by hygroscopic strains between the pin and pinhole boundary condition shows similar color of model. Load step 2 will be set up through a moving pin with $0.018 \mathrm{~m}$ out of board member with a hole and using degree of freedom (DOF) displacement conditions on coupled nodes shows in pink color. Explicitly automatic time stepping will be considered in support to guarantee solution convergence.

Fig-2 (b) shows, the contact between the plate and pin member with a centrally hole where model using a contact pair of elements, Target is plate surface 170 and Contact member surface is 174 , respectively.

Fig-2 shows the boundary condition are applied by setting the left side surface of board member with hole to be fixed. The interference fit between the plate and pin member with hole as modeled by structural static loads.

\subsection{Assumption}

Solid plate will be assumed as behavior of material is orthotropic with three mutually perpendicular material principal axes, namely, longitudinal, radial, and tangential axes respectively.

\section{ANSYS RESULTS}

\subsection{Type-1: Analysis on Mild Steel Material for}

\section{Both Pin and Plate}

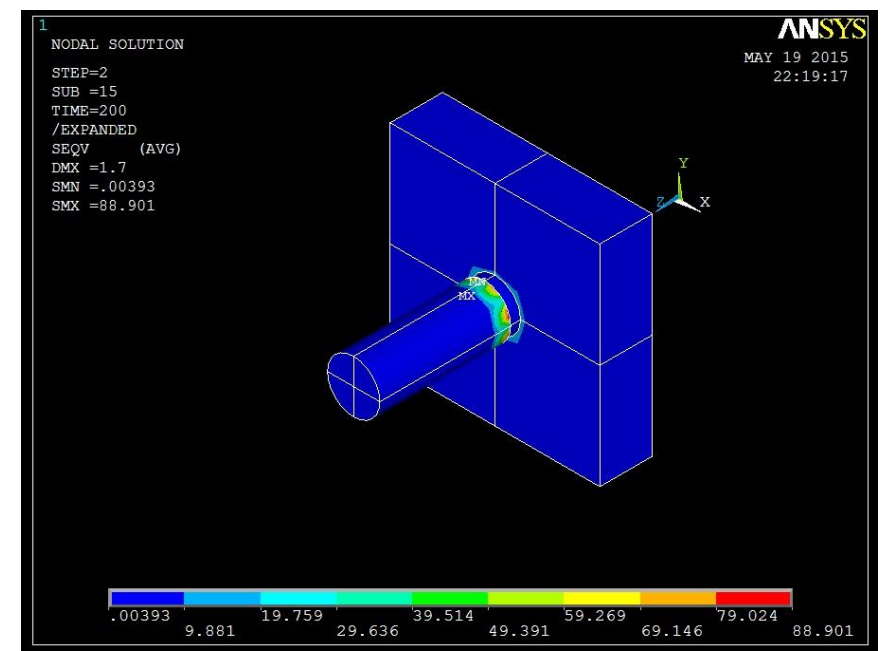

Fig-3: Radial Stress Distribution of model at initial Position

Fig -3 , shows the maximum radial stress $88.901 \mathrm{MPa}$ of the component at initial boundary condition. 


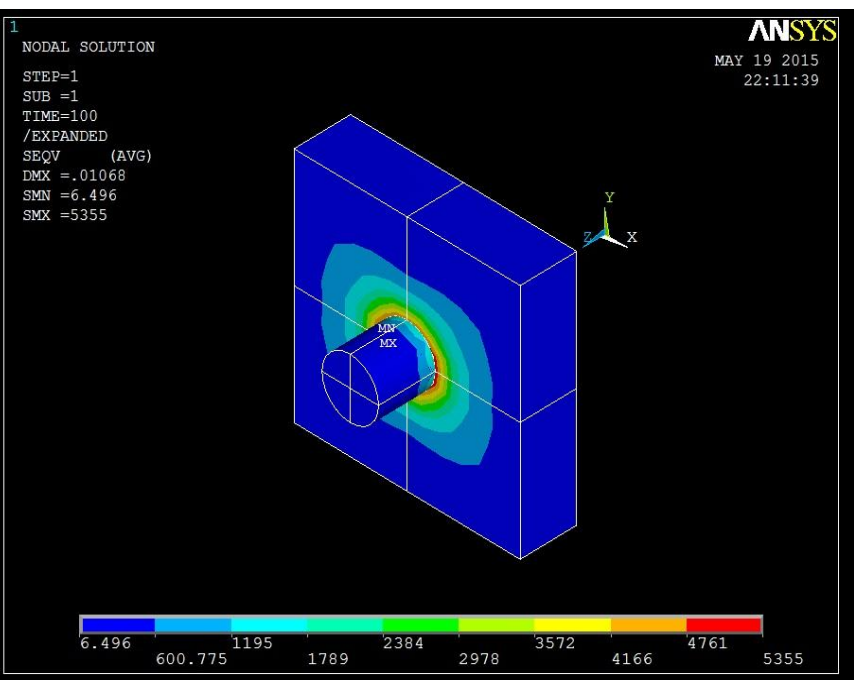

Fig-4: Radial Stress Distribution of model at final Position

Fig -4, shows the maximum radial stress $5755 \mathrm{MPa}$ of the component at final boundary condition.

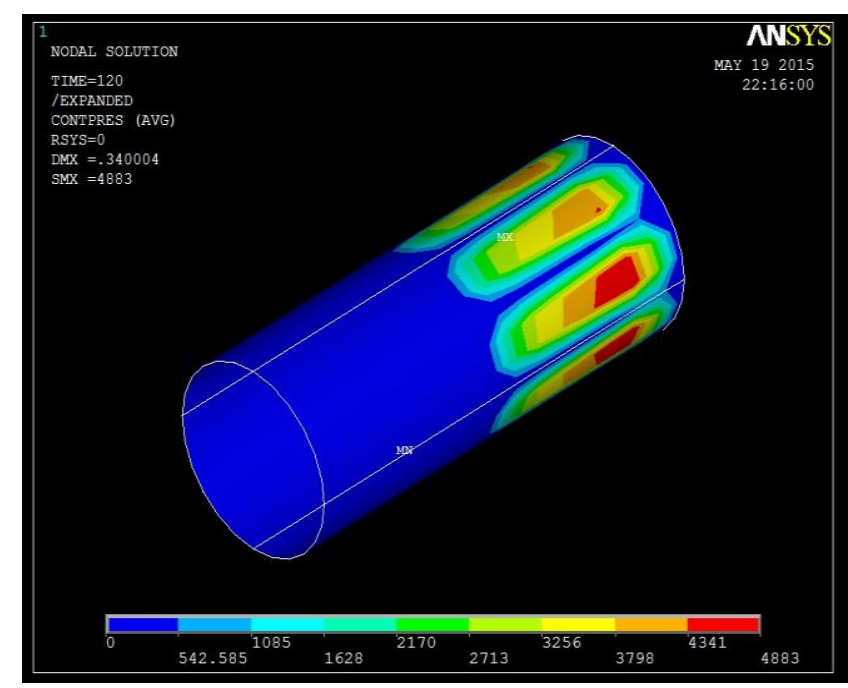

Fig-5 Contact Pressure Distribution

Fig-5 shows, contact pressure distribution at the surface of pin inner circumferential surface of plate after contact for steel

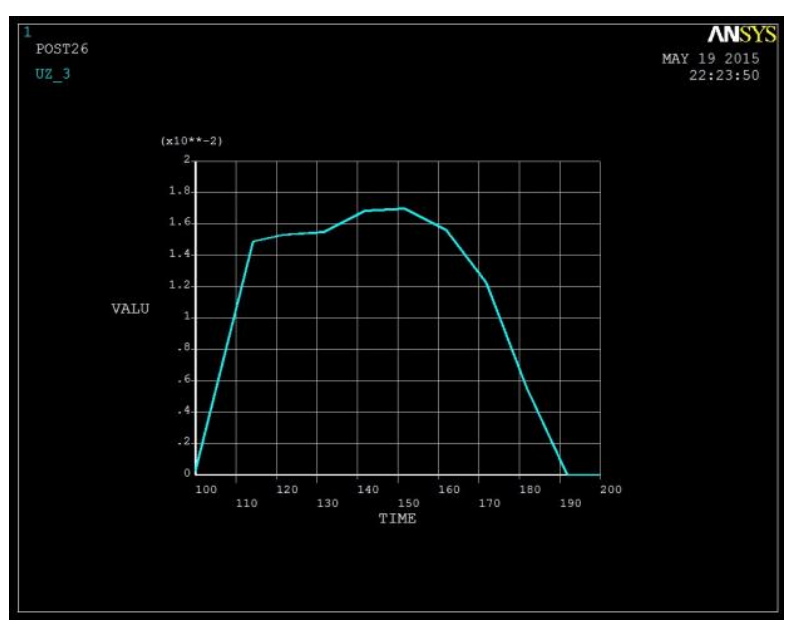

Fig-6 Contact Deformation Graph for Steel
Fig-6 shows contact deformation graph, when fitting of pin occurs deformation takes place due to increase in pin diameter then hole diameter of plate i.e. $1.7 \mathrm{~mm}$.

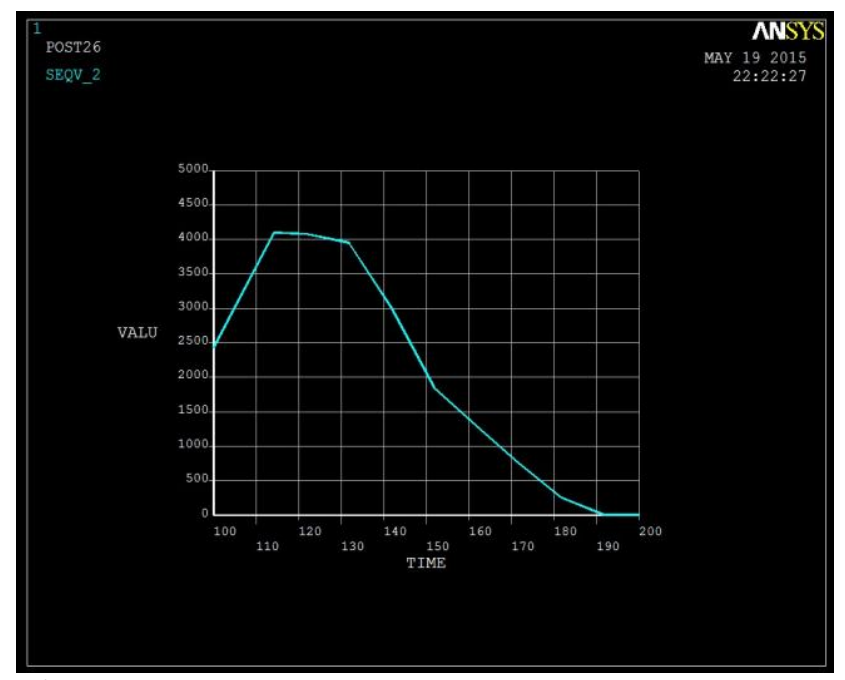

Fig-7. max. von misses stress distribution vs time for steel

Fig-7 shows that Maximum stress distribution with respect to time $5755 \mathrm{MPa}$.

\subsection{Type-2: Analysis on Aluminium Material for}

\section{Both Pin and Plate}

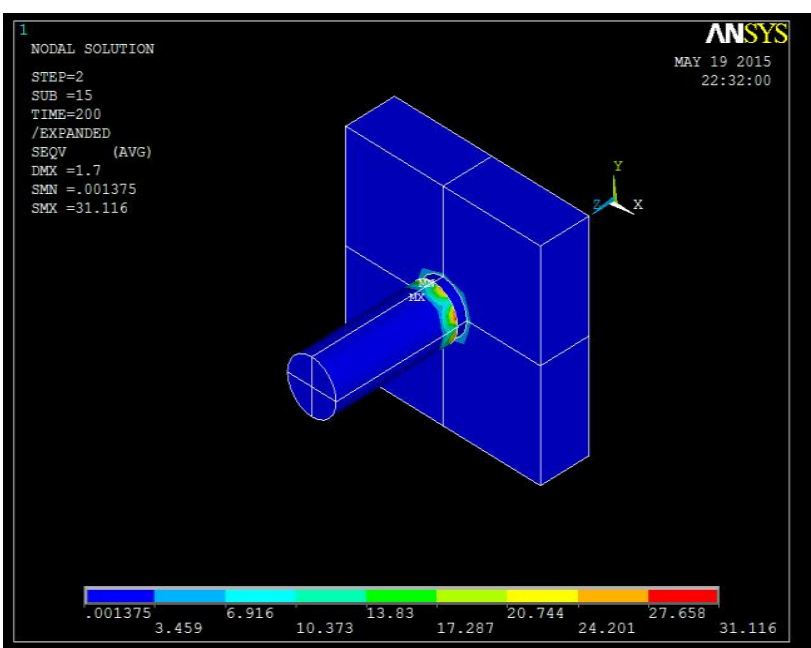

Fig-8: Contact Stress Distribution of model at initial Position for Aluminium

Fig -8 , shows the maximum radial stress $33.114 \mathrm{MPa}$ of the component at initial boundary condition. 


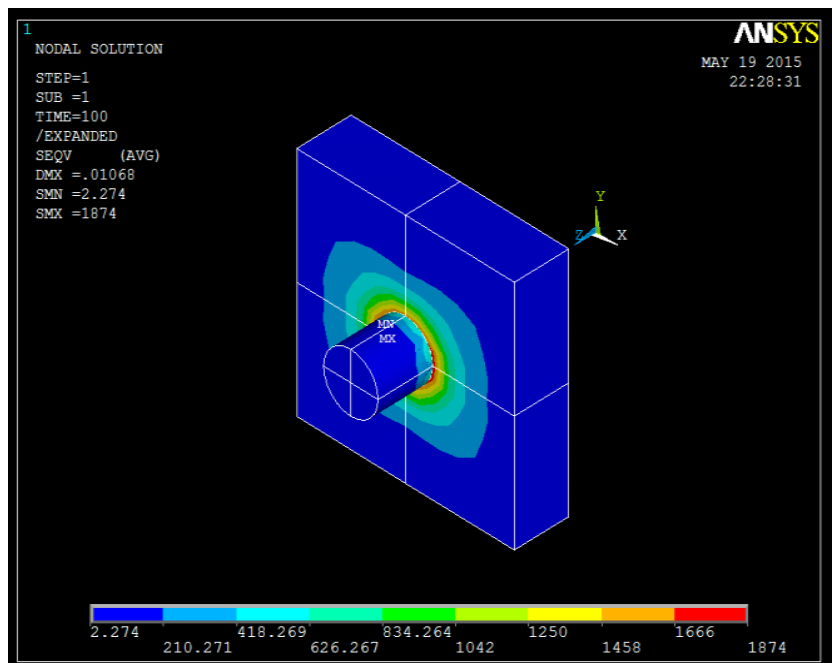

Fig-9. Contact Stress Distribution of model at Final Position for Aluminium

Fig -9, shows the maximum radial stress $1874 \mathrm{MPa}$ of the component at final boundary condition.

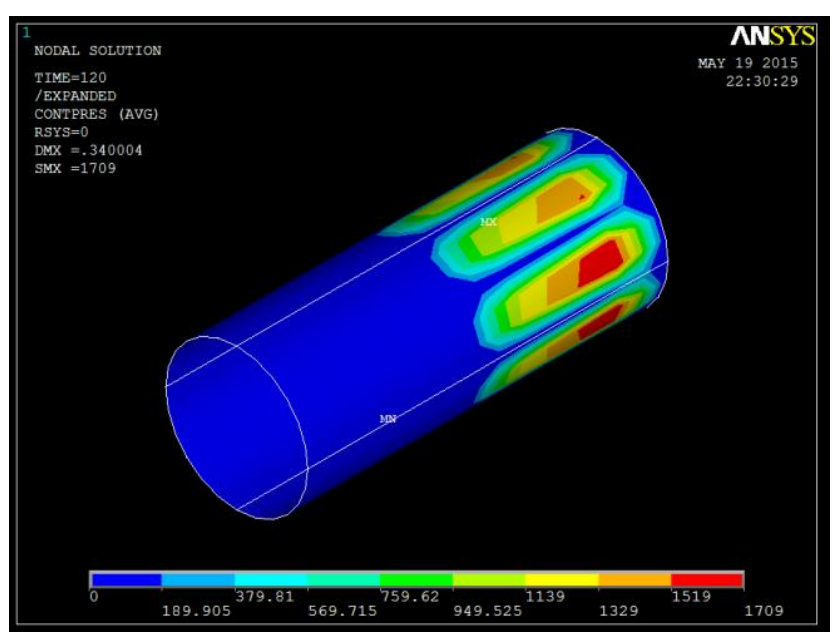

Fig-10. Contact Pressure Distribution at the surface of pin after contact for Aluminium

Fig-10 shows, contact pressure distribution at the surface of pin inner circumferential surface of plate after contact for steel

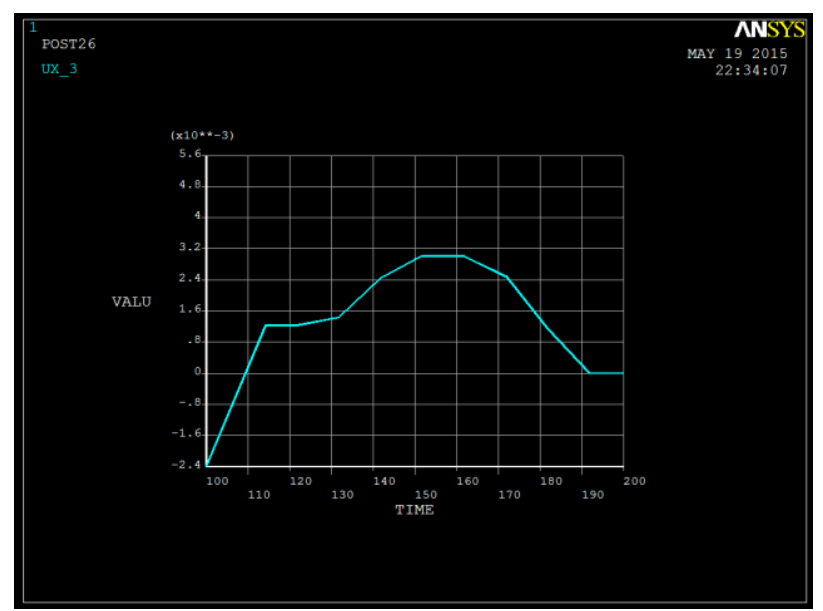

Fig-11.: Contact Deformation Graph for Aluminium
Fig-11 shows contact deformation graph, when fitting of pin occurs deformation takes place due to increase in pin diameter then hole diameter of plate i.e. $0.01066 \mathrm{~mm}$.

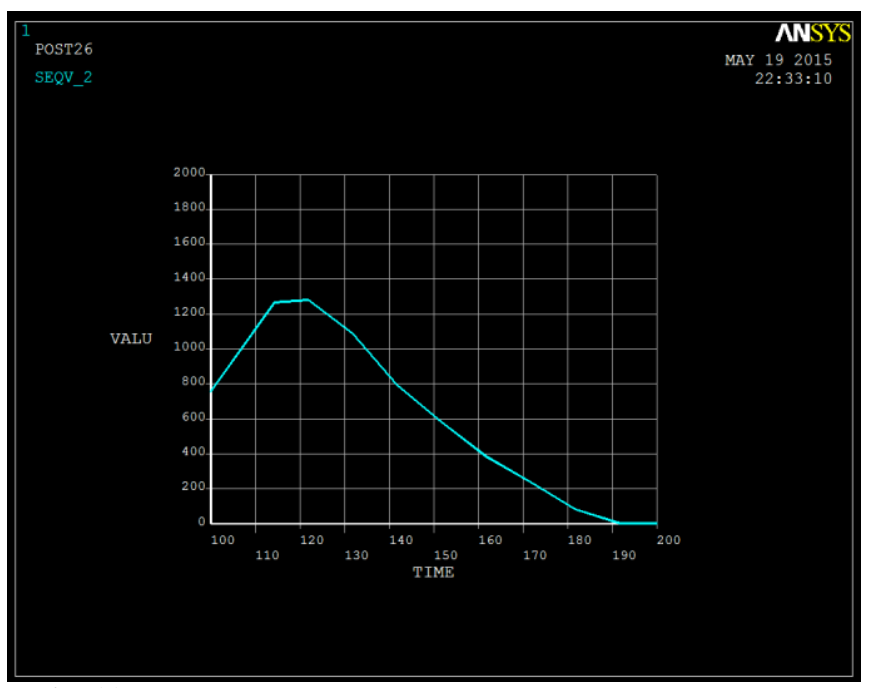

Fig-12. Max. Von misses Stress Distribution Vs Time for Aluminium

Fig-7 shows that Maximum stress distribution with respect to time $1874 \mathrm{MPa}$.

\subsection{Discussion}

$>\quad$ The Maximum contact Stress distribution of 88.901 Mpa and deformation of $0.01 \mathrm{~mm}$ is obtained at initial contact and Maximum contact Stress distribution of $5355 \mathrm{Mpa}$ and deformation of $1.7 \mathrm{~mm}$ is obtained at the final position of Contact for Stainless steel material.

$>\quad$ The Maximum contact Stress distribution of 31.116 Mpa and deformation of $0.1 \mathrm{~mm}$ is obtained at initial contact and Maximum contact Stress distribution of $1874 \mathrm{Mpa}$ and deformation of $0.01066 \mathrm{~mm}$ is obtained at the final position of Contact for Aluminium alloy material.

\section{CONCLUSION}

On the base of this study, the following conclusions could be drawn:

$>$ The analysis and design of interference fit for Plate and pin assembly joint can be performed by using commercial FEM packages.

$>\quad$ The Maximum contact Stress distribution of 88.901 Mpa and deformation of $0.01 \mathrm{~mm}$ is obtained at initial contact and Maximum contact Stress distribution of $5355 \mathrm{Mpa}$ and deformation of $1.7 \mathrm{~mm}$ is obtained at the final position of Contact for Stainless steel material.

$>\quad$ The Maximum contact Stress distribution of 31.116 Mpa and deformation of $0.1 \mathrm{~mm}$ is obtained at initial contact and Maximum contact Stress distribution of $1874 \mathrm{Mpa}$ and deformation of $0.01066 \mathrm{~mm}$ is obtained at the final position of Contact for Aluminium alloy material. 
$>$ The Obtained strength of model was influenced by these two factors (Material Properties, Geometry of the model, Loads and Boundary conditions. and the best design of joint to obtain highest withdrawal strength of dowel was found using properties of Stainless steel.

\section{ACKNOWLEDGEMENTS}

I am deeply and Hartley thanks to my parents and my friends for encouraging and helping me to prepare the project.

\section{REFERENCES}

[1] Vahid Monfared et al: "Contact stress analysis in rolling bodies by finite element method(FEM) statically", Journal of mechanical engineering and automation, Vol 2,2012.

[2] Zhengui Zhang et al: "Mechanism and effect of mallet tapping on contact stress distribution between V-band clamp and piping system" ,International Journal of Industrial engineering and management, Vol 5,no:2,2014.

[3] Aslam Pasha Taj et al: "Effect of sleeve shrink fit on bearing preload of a machine tool spindle: Analysis using FEM",All india manufacturing technology ,design and research conference ,Dec 2014.

[4] Buket Okutan et al: "Stress and failure analysis of laminated composite pinned joints", Graduate school of natural applied science thesis, Vol 1,2001.

[5] Matthew Forcier et al: "Analytical modelling of edge-of-contact stresses due to sliding contact as it varies with friction, fidelity of model and stress relievers", International Journal, Vol 1,2008.

[6] Irappa Sogalad et al: "A comparative study of stress distribution in interference fitted assemblies", Indian journal of engineering and material sciences, Vol 13,2006 .

[7] Zhengui Zhang et al: " Contact stress analysis of interference fit between V-band clamp and piping system", International journal of engineering and innovative technology, Vol 4,issue 3,Sep 2014.

[8] Ramanandan H.S et al: " Elasto plastic thermal stress analysis of interference fit in turbo charger's swing valve assembly by estimating Von-mises stress distribution",IJIET, Vol 3,Issue 1,Oct 2013.

[9] Chris Truman et al: "Residual stresses in machined and shrink fitted assemblies",JCPDS-International centre for diffraction data,2009.

[10] John H. Crews et al: "An elastic analysis of stresses in a uniaxially loaded sheet containing an interference-fit bolt" ,NASA, oct 1972.

[11] J.C Perez Cerdian et al: "Analysis of contact stresses in interference fit joints with circumferential round notch on the hub", World congress in mechanism and machine science, mexico, June 2011.

[12] Irappa Sogalad et al: "Cryogenic treatment effect on stress distribution in interference fitted assemblies", IJMSP, Vol 7,2006.
[13] Xiao-Yang Niu et al: " Finite element analysis of interference fit between car swing arm and shaft sleeve", Journal of chemical and pharmaceutical reaserch, 2015.

[14] D.Croccolo et al: " Interference fit effect on holed single plate loaded with tension-tension stresses",Fracttura ed integritta structural,21,2012.

[15] Lijesh K.P et al: "Finite element analysis of steam turbine coupling, International journal of current engineering and technology, Vol 5,no:2, 2015.

\section{BIOGRAPHIES}

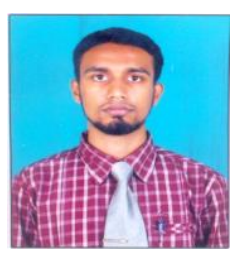

Asst. Prof., Department of Mechanical Engineering, Ghousia College of Engineering, Ramanagaram, Karnataka, India

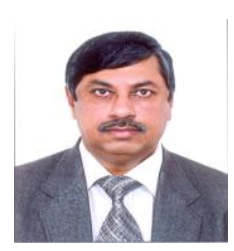

Principal \& Professor, Department of Mechanical Engineering, Ghousia College of Engineering, Ramanagaram, Karnataka, India

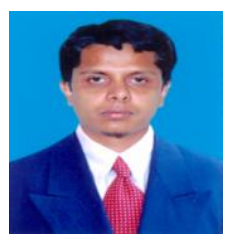

Asst. Prof., Department of Mechanical Engineering, Ghousia College of Engineering, Ramanagaram, Karnataka, India 